\title{
ERROS NA MEDICAÇÃo e CONSEQÚÉncias PARA PROFISSIONAIS de ENFERMAGEM E CLIENTES: UM ESTUDO EXPLORATÓRIO
}

\author{
Viviane Tosta de Carvalho ${ }^{1}$ \\ Silvia Helena De Bortoli Cassiani ${ }^{2}$
}

Carvalho VT, Cassiani SHB. Erros na medicação e conseqüências para profissionais de enfermagem e clientes: um estudo exploratório. Rev Latino-am Enfermagem 2002 julho-agosto; 10(4):523-9.

O objetivo deste estudo foi analisar as conseqüências de erros ocorridos para os pacientes e profissionais de enfermagem com base em relatos de erros. O estudo foi realizado em um hospital do estado de São Paulo, em 1999. Adotou-se como referencial metodológico a Técnica do Incidente Crítico modificado. Os dados foram extraídos das entrevistas realizadas com 7 enfermeiros, 1 técnico e 23 auxiliares de enfermagem. Na análise foram identificadas conseqüências do erro para o paciente e para o profissional de enfermagem. Conclui-se a necessidade de se notificarem os erros na medicação para que se verifiquem suas causas, índices e conseqüências por parte das instituições hospitalares, uma vez que as taxas de erros na medicação representam matéria - prima para inúmeras investigações e constituem-se em indicadores para a melhoria do sistema hospitalar e da qualidade de assistência.

DESCRITORES: erros de medicação, enfermagem

\section{MEDICATION ERRORS AND CONSEQUENCES FOR NURSING PROFESSIONALS AND CLIENTS: AN EXPLORATORY STUDY}

This study, which was conducted in a hospital in São Paulo State, Brazil in 1999, aimed at analyzing the consequences of medication errors for patients and nursing professionals based on error reports. The Critical Incident Technique with modifications was adopted as a theoretical frameworkl. Data were collected through interviews with 7 nurses, 4 nursing technicians and 23 nursing auxiliaries. The analysis enabled the identification of consequences for patients and for the nursing professionals involved. It was concluded that medication errors must be reported so that their causes, rates and consequences in hospitals can be observed, considering that medication error rates are the sources for various studies as well as indicators for the improvement of the hospital system and care quality.

\section{ERRORES EN LA MEDICACIÓN Y CONSECUENCIAS PARA lOS PROFEsIONALES de ENFERMERIA Y PACIENTES: UN ESTUDIO EXPLORATORIO}

El objetivo de este estudio fue analizar las consecuencias del los errores ocurridos con base en los relatos de los profesionales de enfermería de un hospital en el interior de Estado de São Paulo, Brasil. Fueron entrevistados 7 enfermeros, 1 técnico de enfermería y 23 auxiliares de enfermería. El referencial metodológico adoptado fue la técnica del incidente crítico modificada. Del análisis de relatos se identificaron las consecuencias que fueron divididas en: consecuencias para el paciente y para el profesional de enfermería.

DESCRIPTORES: errores de medicamentos, enfermería

\footnotetext{
${ }^{1}$ Enfermeira, Mestre, Resumo da dissertação de mestrado; ${ }^{2}$ Orientadora do estudo, Professor Associado, e-mail: shbcassi@eerp.usp.br. Escola de Enfermagem de Ribeirão Preto, da Universidade de São Paulo, Centro Colaborador da OMS para o desenvolvimento da pesquisa em enfermagem
} 


\section{INTRODUÇÃO}

Os medicamentos administrados erroneamente podem afetar os pacientes, e suas conseqüências podem causar prejuízos/danos, reações adversas, lesões temporárias, permanentes e até a morte do paciente, dependendo da gravidade da ocorrência.

Lesões não intencionais associadas à terapia medicamentosa têm afetado 1,3 milhões de pessoas por ano nos Estados Unidos da América e o custo relacionado à hospitalização do paciente devido ao efeito adverso chega a atingir, anualmente, 76,6 bilhões de dólares ${ }^{(1)}$.

Importa ressaltar que, nos Estados Unidos da América, o número de pacientes atingidos anualmente, representa um montante de 60.000 a 140.000 pacientes. Destes, $31 \%$ vivenciam um evento adverso de medicação durante a hospitalização, e 0,31\% destes apresentam eventos adversos fatais ${ }^{(2)}$.

A classificação da severidade dos erros de medicação foi realizada por diversos autores ${ }^{(3-4)}$ que avaliaram a gravidade do erro, segundo a necessidade de intervenções médicas, realização de tratamentos cirúrgicos e intervenções de enfermagem.

Muitas vezes, os erros de medicação só são detectados quando as conseqüências são clinicamente manifestadas pelo paciente, tais como a presença de sintomas ou reações adversas após algum tempo em que foi ministrada a medicação, alertando o profissional do erro cometido. Os profissionais de enfermagem deveriam estar alerta e, após administrada a medicação, esta deve ser documentada imediatamente no registro do paciente, possibilitando rapidamente a descoberta do erro pelo enfermeiro e a realização de intervenções que podem minimizar ou prevenir possíveis complicações ou conseqüências mais graves.

Infelizmente, as dificuldades para os relatos dos erros prejudicam a avaliação dos tipos e do número de erros registrados e, conseqüentemente, não é documentado o número real de erros ocorridos. O número de erros relatados nas instituições hospitalares representa apenas a ponta do iceberg, já que somente são informados quando há algum dano ao paciente. Apenas $25 \%$ dos erros são relatados pelos profissionais ${ }^{(5)}$. 0 medo de punições, demissão, o sentimento de culpa e as preocupações com a gravidade do erro podem levar os indivíduos envolvidos a sub-notificarem o erro. As penalidades ao profissional envolvido variam conforme a gravidade das lesões corporais causadas ao paciente e o tipo de conseqüência. Os profissionais podem sofrer processos judiciais por negligência, imprudência, má prática, e ficar sob julgamento da legislação civil, penal e ética.

Os erros freqüentemente não são relatados devido ao medo das medidas administrativas que podem ser aplicadas ao profissional envolvido, de acordo com a gravidade do erro cometido.Concluiu-se que $29 \%$ dos erros de medicação ocorridos não foram relatados pelos enfermeiros devido ao medo das conseqüências punitivas, com as quais se procura cercear o relato espontâneo do erro ${ }^{(6)}$.

Buscando identificar esse aspecto na realidade nacional, esse estudo foi planejado com o objetivo de identificar e analisar as conseqüências dos erros de medicação para o paciente e para os profissionais de enfermagem.

Pretendeu-se enfocar os aspectos relativos aos erros na medicação em uma instituição hospitalar, privilegiando, através dos relatos de profissionais de enfermagem, as possíveis conseqüências de erros cometidos ou conhecidos.

\section{METODOLOGIA}

O estudo foi realizado em um hospital universitário do Estado de São Paulo.

A população em estudo e atuante no setor era composta por 10 enfermeiros, 4 técnicos e 46 auxiliares de enfermagem. Foram excluídos os enfermeiros que estavam em cargo de chefia.

A amostra ficou constituída por 7 enfermeiros, 1 técnico de enfermagem e 23 auxiliares de enfermagem, sendo que, do total de enfermeiros, 1 estava em licença saúde, 1 recusou-se participar do estudo e 1 relato foi inválido. Do total de 46 auxiliares de enfermagem alocados, 11 recusaram-se a participar do estudo, 1 estava em licença saúde, 1 tinha sido demitido, 1 havia sido transferido para outro setor. Do total de 32 auxiliares de enfermagem entrevistados, 8 não recordaram nenhum fato e 1 apresentou relato inválido. Relatos inválidos foram considerados aqueles relatos vagos, imprecisos e incompletos, que não apresentavam as conseqüências dos erros tanto para pacientes como para profissionais de enfermagem. 
Dos 4 técnicos entrevistados: 1 não recordou nenhum fato, 1 recusou participação e 2 forneceram relatos inválidos. Assim foram realizadas 31 entrevistas com 46 relatos de erros ocorridos e válidos. Relatos válidos foram considerados aqueles relatos completos e precisos sobre os erros ocorridos. Há de considerar que, em alguns casos, obteve-se mais de um relato por entrevista.

A técnica do incidente crítico consiste de um conjunto de procedimentos para a coleta de observações diretas do comportamento humano, de modo a facilitar sua utilização potencial na solução de problemas práticos e no desenvolvimento de amplos princípios psicológicos, delineando, também, procedimentos para a coleta de incidentes observados, que apresentam significado especial, e para o encontro de critérios sistematicamente definidos". O autor ainda define incidente como "qualquer atividade humana observável que seja suficientemente completa em si mesma para permitir inferências e previsões a respeito da pessoa que executa o ato"(7).

Portanto, o incidente crítico prevê a análise de uma ocorrência crítica que marcou as pessoas. Neste estudo, utilizamos uma adaptação da técnica do incidente crítico, já que foram abordados somente os aspectos negativos.

O instrumento de coleta de dados constou de um roteiro de entrevista para obtenção de relatos de erros ocorridos na medicação, de acordo com o objetivo do estudo. $\mathrm{O}$ instrumento foi submetido a um pré teste com uma enfermeira mestranda, atuante em um hospital, um técnico de enfermagem e um auxiliar de enfermagem, atuantes no hospital em estudo, porém em outro setor.

A coleta de dados foi realizada nos meses de agosto e setembro de 1999, após aprovação do estudo pelo Comitê de Ética em Pesquisa do Hospital em questão e o consentimento da divisão e diretoria de enfermagem da unidade.

Após o consentimento informado dos participantes do estudo, as entrevistas foram realizadas na própria instituição hospitalar, durante o período de trabalho e transcorreu, em média, de 15 a 30 minutos. A questão abordada foi: "Pense em alguma coisa negativa que ocorreu na administração de medicamentos recentemente, com pacientes da sua unidade. Pense em uma ocorrência que lhe chamou a atenção e resultou em um erro na medicação. Conte-me quais foram as conseqüências para o paciente e para o profissional".
As entrevistas foram gravadas em fita cassete $e$ transcritas na íntegra, imediatamente após o seu término. Foi mantido o anonimato dos entrevistados.

Após a coleta dos dados, iniciou-se a análise das entrevistas, procedendo-se à leitura dos relatos e identificação e análise das conseqüências. CONSEQÜÊNCIA foi definida como o resultado do erro na medicação para o paciente e para o profissional envolvido.

\section{RESULTADOS}

As conseqüências dos erros foram classificadas segundo a pessoa afetada (pacientes e profissionais de enfermagem) e segundo o momento de sua ocorrência (até 24 horas e após esse período). Formaram-se assim quatro grupos de análise, a saber:

a) conseqüências para os pacientes nas primeiras 24 horas;

b) conseqüências para os profissionais de enfermagem nas primeiras 24 horas;

c) conseqüências tardias para os pacientes;

d) conseqüências tardias para os profissionais de enfermagem.

Tabela 1 - Conseqüências de 48 erros para os pacientes nas primeiras 24 horas, segundo os profissionais de enfermagem. Ribeirão Preto, 1999

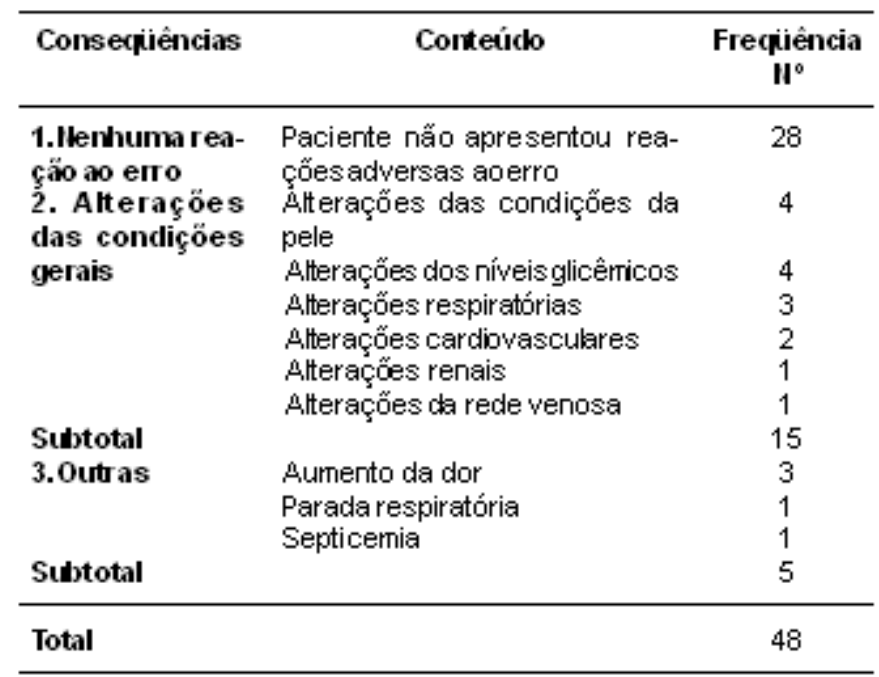

A Tabela analisa o primeiro desses quatro grupos, as Conseqüências para os pacientes nas primeiras 24 horas (48), relatadas pelos profissionais de enfermagem, agrupadas em 3 categorias:

1. Nenhuma reação ao erro- Nessa categoria foram 
incluídos 28 relatos, que indicavam que os pacientes não sofreram nenhuma reação adversa ao erro de medicação. 2. Alterações das condições gerais - Nessa categoria foram incluídos 15 relatos relacionados às alterações que causaram danos ou prejuízos temporários aos pacientes, divididos em: alterações das condições da pele (04)presença de hematoma, edema, hiperemia do local, necrose tecidual; alterações dos níveis glicêmicoshipoglicemia (04); alterações respiratórias - dispnéia (03); alterações cardiovasculares- taquicardia (02); alterações renais- diminuição da diurese e aumento do edema (01); alteração da rede venosa (01).

3. Outras - Estiveram incluídas: dor, infecção generalizada e parada respiratória. Em 03 relatos, o paciente apresentou dor devido ao erro, em 1 relato o paciente apresentou septicemia nas primeiras 24 horas seguidas ao erro de medicação, e, em 1 relato, o paciente recebeu a medicação errada (psicotrópico) e sofreu uma parada respiratória seguida por atendimento de urgência.

A Tabela analisa as conseqüências dos erros para os profissionais de enfermagem nas primeiras 24 horas, demonstrando o aumento do tempo dispendido pela equipe de enfermagem para a reversão do quadro, devido ao erro cometido e à necessidade de realização de intervenções extras pela equipe de enfermagem.

Tabela 2 - Distribuição das conseqüências para os profissionais de enfermagem nas primeiras 24 horas, segundo os relatos e seus respectivos conteúdos e freqüências. Ribeirão Preto, 1999

\begin{tabular}{|c|c|c|}
\hline Consecpiências & Conteúido & $\begin{array}{l}\text { Frecpiência } \\
\text { II }^{\circ}\end{array}$ \\
\hline \multirow{14}{*}{$\begin{array}{l}\text { 1. Intervençöes } \\
\text { deenfermagem } \\
\text { segundo a } \\
\text { prescriçăo mé- } \\
\text { dica }\end{array}$} & $\begin{array}{l}\text { Verificaçấo dos sinais vitais } \\
\text { Inter rupçấo da infusấo endo- }\end{array}$ & $\frac{10}{7}$ \\
\hline & $\begin{array}{l}\text { Venosa } \\
\text { Administraçẫo de medicamentos } \\
\text { extras }\end{array}$ & 6 \\
\hline & $\begin{array}{l}\text { Troca da punçấo venosa em } \\
\text { quimioterapia }\end{array}$ & 4 \\
\hline & Observaçấo de enfermagem & 3 \\
\hline & $\begin{array}{l}\text { Dessensibilizaçấo do local de } \\
\text { infiltraçấo de quimioterapia }\end{array}$ & 2 \\
\hline & $\begin{array}{l}\text { Aplicaçấo de gelo no local de } \\
\text { infitraçấo }\end{array}$ & 2 \\
\hline & $\begin{array}{l}\text { Irrigaçấo da veia com soro } \\
\text { fisiógóico }\end{array}$ & 1 \\
\hline & Manutençấo de repouso no leito & 1 \\
\hline & Realizaçáo de lavagem gástrica & 1 \\
\hline & $\begin{array}{l}\text { Reprogramaçấo da bormba de } \\
\text { infusấo endovenosa }\end{array}$ & 1 \\
\hline & Oxigenderapia & 1 \\
\hline & Adrninistraçáo de líquidos via oral & 1 \\
\hline & $\begin{array}{l}\text { com açúcar } \\
\text { Colneifa de exames extras }\end{array}$ & 4 \\
\hline & $\begin{array}{l}\text { Auxilio no atendimento de } \\
\text { urgếncia }\end{array}$ & 1 \\
\hline Total & & 46 \\
\hline
\end{tabular}

As conseqüências para os profissionais de enfermagem nas primeiras 24 horas (46), estão agrupadas na categoria: Intervenções de enfermagem segundo a prescrição médica. Entende-se por intervenções ou tratamentos a solicitação de procedimentos extras para reverter o quadro apresentado pelo paciente frente ao erro nessa categoria, foram incluídos 46 relatos assim descritos: verificação dos sinais vitais (10), interrupção da infusão endovenosa (7), administração de medicamentos extras por ordem médica (6), troca da punção venosa em quimioterapia (4), solicitação de exames extras (4), observação de enfermagem quanto a sinais de hipoglicemia e do local de infiltração de quimioterapia (3), procedimentos de dessensibilização do local de infiltração de quimioterapia (2), aplicação de gelo no local de infiltração de quimioterapia (2). Com algumas ocorrências apareceu irrigação da veia com soro fisiológico, manutenção de repouso no leito, realização de lavagem gástrica, revisão do gotejamento com reprogramação da bomba de infusão endovenosa, oxigenoterapia, administração de líquidos via oral com açúcar, nova prescrição e atendimento de urgência.

A Tabela 3 apresenta as conseqüências dos erros para os pacientes, após as primeiras 24 horas.

Tabela 3 - Distribuição das conseqüências tardias para os pacientes, segundo os profissionais de enfermagem e suas respectivas freqüências. Ribeirão Preto, 1999

\begin{tabular}{|c|c|}
\hline Consequiênciastardiaspara os pacientes & $\begin{array}{c}\text { Frecpiêtencia } \\
\mathbf{H}^{\circ}\end{array}$ \\
\hline $\begin{array}{l}\text { 1. Evolução e alta emboas condiçöes gerais } \\
\text { 2. Evoluçăo e alta compresença de lesöes } \\
\text { 3. Hospitalizaçäo prolongada } \\
\text { 4. Óbito }\end{array}$ & $\begin{array}{l}5 \\
3 \\
3 \\
2\end{array}$ \\
\hline Total & 13 \\
\hline $\begin{array}{l}\text { As Conseqüências tardias para } \\
\text { relatadas pelos profissionais de enferr } \\
\text { agrupados em } 4 \text { categorias discriminadas } \\
\text { 1. Evolução e alta em boas condições } \\
\text { categoria, obteve-se um total de } 5 \text { relatos } \\
\text { pacientes evoluíram e tiveram alta em bo } \\
\text { gerais. } \\
\text { 2. Evolução e alta com presença de le } \\
\text { categoria, foram incluídos três relatos: } \\
\text { paciente teve necrose tecidual, realizou de } \\
\text { região necrosada e obteve alta com presen }\end{array}$ & $\begin{array}{l}\text { pacientes } \\
\text { gem foram } \\
\text { oaixo: } \\
\text { ais - Nessa } \\
\text { os quais os } \\
\text { condições } \\
\text { es - Nessa } \\
1 \text { relato o } \\
\text { damento da }\end{array}$ \\
\hline
\end{tabular}


no dorso da mão; o paciente teve alta com a presença de hematoma (1); o paciente teve alta com seguimento ambulatorial, devido à absorção gástrica de uma parte da quimioterapia administrada (1).

3. Hospitalização prolongada - Em três relatos os pacientes tiveram aumento no tempo de estada no hospital: o paciente que absorveu parte do quimioterápico e os dois pacientes que apresentaram hipoglicemia.

4. Óbito - Em dois relatos, ocorreu o óbito do paciente. Em um relato, o paciente apresentou infecção generalizada nas primeiras 24 horas e, após esse período, foi a óbito e, no outro relato, o paciente apresentou piora do estado geral, com alterações renais nas primeiras 24 horas e foi a óbito após 15 dias da ocorrência do erro, segundo informações dos profissionais.

Não obstante, afirmar que a morte dos pacientes foi devida ao erro de medicação, já que investigações mais completas, conhecimento do histórico, do diagnóstico do paciente, dados de exames laboratoriais e prognóstico do mesmo comparados ao erro ocorrido deveriam ser avaliados pela equipe médica e de enfermagem, para afirmar a relação entre o erro e o óbito.

As conseqüências tardias para os profissionais de enfermagem, extraídas dos relatos, bem como a freqüência com que ocorreram estão indicadas na Tabela 4.

Tabela 4 - Distribuição das conseqüências para os profissionais de enfermagem após 24 horas de ocorrência do erro de medicação. Ribeirão Preto, 1999

\begin{tabular}{|c|c|}
\hline $\begin{array}{c}\text { Consequiências tardias para os profissionais } \\
\text { de erfermagem }\end{array}$ & $\begin{array}{c}\text { Freçiência } \\
\text { II }^{\circ}\end{array}$ \\
\hline 1.Advertência verbal & 17 \\
\hline 2. Ilotificaçäo daocorrência & 12 \\
\hline 3.Orientaçäo & 11 \\
\hline 4. Advertência escrita & 4 \\
\hline 5.Demissäo & 2 \\
\hline Total & 46 \\
\hline
\end{tabular}

Assim, as Conseqüências tardias para os profissionais de enfermagem estão agrupadas em 5 categorias, a seguir:

1. Advertência verbal - Realizada tanto pelo enfermeiro como pela diretoria de enfermagem. Nessa categoria, foram incluídos dezessete relatos.
2. Notificação da ocorrência - Nessa categoria, foram incluídos doze relatos em que os profissionais de enfermagem receberam um relatório seguido de advertência escrita, realizado pelo enfermeiro e diretoria da enfermagem.

3. Orientação - Nessa categoria, em onze relatos ocorreu apenas a orientação do funcionário pelo enfermeiro.

4. Advertência escrita - Em quatro relatos, o enfermeiro fez advertência por escrito para o profissional envolvido. 5. Demissão - Em dois relatos, ocorreu a demissão do profissional de enfermagem.

As medidas administrativas tomadas com a maioria dos profissionais envolvidos, segundo seus próprios relatos, foram: 1. advertência verbal, 2 . notificação da ocorrência; 3.orientação; 4. advertência escrita e 5. demissão. O relatório não foi visto como forma de registro do erro, mas, sim, como uma penalidade a que os profissionais são expostos por terem cometido o erro.

Fica-se evidente que as medidas tomadas pela chefia são, na maioria, relatos de caráter punitivo. No entanto, tal medida pode acarretar subnotificações e diminuição dos relatos voluntários dos erros de medicação.

A chefia adota essa posição, na esperança de que os profissionais não cometam mais erros de medicação. É o que se depreende deste relato:

Você não deixa de fazer nada, mesmo que seja uma orientação verbal, eles têm que estar cientes do que eles fizeram, eu oriento verbalmente num primeiro atenuante, no segundo eu oriento por escrito e num grave até suspensão, é feita uma punição sim, não é passado em branco... (E.2).

$\mathrm{Na}$ elaboração do relatório, o funcionário é chamado para relatar quando, como e por que o erro ocorreu; é anotado o dia, a hora, o período do plantão; a assinatura do funcionário consta no final da descrição. A elaboração da notificação do erro, para muitos funcionários, já constitui uma penalidade.

Ressalta-se que o relato dos erros na medicação, a fim de que haja intervenções, deve ser enfatizado nas instituições, e que os mesmos devem ser avaliados e incorporados em um programa de melhoria contínua da qualidade $^{(8)}$.

Os relatos dos erros de medicação não devem ser vistos com esse propósito punitivo, mas como dados que permitam o desenvolvimento de ações educacionais 
e administrativas.

$\mathrm{Na}$ ocorrência de um erro na medicação, freqüentemente, não é dada ênfase na educação, mas, sim, na punição, lembrando que isso, ao invés de ajudar a prevenir, faz com que, cada vez menos, os erros sejam relatados, prejudicando o conhecimento de seus fatores de risco e possibilitando, assim, sua repetição ${ }^{(9)}$.

\section{DISCUSSÃO}

Fornecer um ambiente seguro para a administração de medicamentos envolve um grande número de recursos, tanto físico (luminosidade, controle de temperatura, barulho, interrupções pessoais ou por telefone) como humanos (deficiência de conhecimentos, anos de experiência). Entretanto, tais condições não isentam os profissionais da responsabilidade exigida pelos danos que praticam.

É o dano sofrido pelo paciente que determinará a existência real do erro. O nexo causal estabelecido entre a causa (ato) e o dano, é condição indispensável para a comprovação dos fatos e para a determinação do grau da pena e indenizações em processos jurídicos, podendo comportar ações civis e penais ${ }^{(10)}$.

Somente ao se identificarem os erros sistemáticos, é que o número real de erro pode ser reduzido. Para a autora, ações punitivas incutem o medo e a decepção e não têm lugar na prática atual. A autora salienta que ênfase na educação faz-se necessária para a modificação da prática atual ${ }^{(11)}$.

A necessidade de educação profissional através da educação continuada, cursos de reciclagem ou treinamentos periódicos na administração de medicamentos é enfatizada para nós, pois, assim, os profissionais assumirão a parcela da responsabilidade que a profissão lhes confere, sem apresentar reações de medo perante o erro.

Temos consciência da dificuldade para a implementação e confecção de tais relatórios; entretanto, os responsáveis não podem esquivar-se de registrá-los, servindo como amparo legal na instalação de um processo ético, civil ou penal.
A crença vigente entre os administradores é a de que os erros são puramente responsabilidade dos indivíduos envolvidos, negando qualquer responsabilidade administrativa ou da instituição ${ }^{(8)}$. Entretanto os erros representam um sistema "doente", e raramente o indivíduo é a única causa de um erro na medicação. Há de se avaliar o sistema e permitir que se evitem falhas.

Há a necessidade crescente da verificação das causas, índices e conseqüências dos erros na medicação, por parte das instituições hospitalares, uma vez que as taxas de erros na medicação representam matéria - prima para inúmeras investigações e constituem-se em indicadores para a melhoria do sistema hospitalar e da qualidade de assistência. Ainda, disseminar uma cultura de segurança que a inclua na medicação deve ser meta das instituições.

\section{CONCLUSÃO}

Por meio dos dados obtidos, foram identificadas as conseqüências dos erros de medicação ao profissional envolvido. Destaca-se que os relatórios foram vistos como ações punitivas, o que prejudica, sem dúvida, o relato voluntário e espontâneo ao se decidir por documentar ou não o erro.

É importante ressaltar a importância do ato de comunicar e documentar o erro de medicação e o benefício que esse ato pode trazer aos pacientes, amenizando os efeitos apresentados e impedindo o agravamento da suas condições físicas. As medidas administrativas tomadas deveriam enfatizar o relato correto como forma de registro para o hospital e como proteção legal, caso ocorra a licitação de um processo ético ou jurídico.

\section{AGRADECIMENTOS}

À FAPESP- Fundação de Amparo à Pesquisa do Estado de São Paulo, pelo recurso financeiro concedido. 


\section{REFERÊNCIAS BIBLIOGRÁFICAS}

1. Allen EL, Barker KN, Cohen MR. Draft guidelines on preventable medication errors. Am J Hosp Pharm 1992 Mar; 49(3):640-8.

2. Classen DC, Pestotnik SL, Evans SR, Burke JP. Adverse drug events in hospitalized patients. JAMA 1997; 277(4):3016.

3. Cobb MD. Evaluating medication errors. J Nurs Adm 1986 Apr; 16(4):41-4.

4. Ernest MA. A judgment of errors. Nurs Times 1991 Apr; 87(14):26-30.

5. Hackel R, Butt L, Banister G. How nurses perceived medication errors. Nurs Manage 1996; 27(1):31-4.

6. Barker KN, Mikeal RL, Pearson RE, Illig NA, Morse ML. Medication errors in nursing homes and small hospitals. Am J Hosp Pharm 1982 Jun; 39:987-91.

7. Flanagan JC. A técnica do incidente crítico. Arq Bras Psicol Apl 1973 Abr/Jun; 21(5):99-141.

8. Cassiani SHB. Um salto para o futuro no ensino da administração de medicamento: desenvolvimento de um programa instrucional auxiliado pelo computador. [tese]. Ribeirão Preto (SP): Escola de Enfermagem de Ribeirão Preto/ USP; 1998

9. Cohen MR. Banish a system that blames. Nursing 1996; 26(1):15.

10. Gomes JCM. Erro médico: reflexões. Bioética 1994; 2(2):139-46.

11. Pepper GA. Errors in drug administration by nurses. Am J Health Syst Pharm 1995; 52(15):390-5. 